Document downloaded from:

http://hdl.handle.net/10251/82848

This paper must be cited as:

Guardiola, C.; Pla Moreno, B.; Bares-Moreno, P.; Waschl, H. (2016). Adaptive calibration for reduced fuel consumption and emissions. Proceedings of the Institution of Mechanical Engineers, Part D: Journal of Automobile Engineering. 230(14):2002-2014. doi:10.1177/0954407016636977.

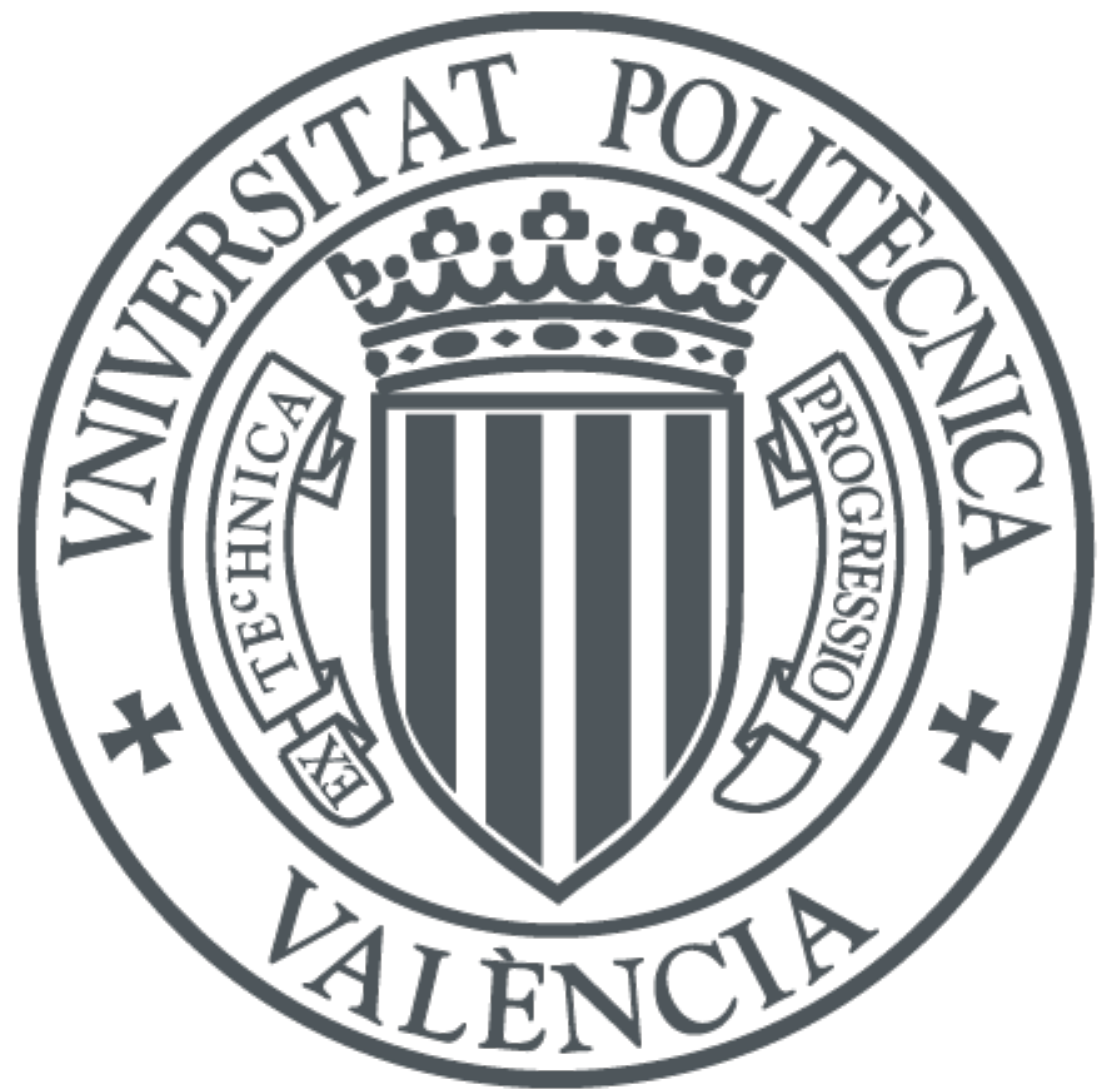

The final publication is available at

http://doi.org/10.1177/0954407016636977

Copyright SAGE Publications (UK and US)

Additional Information 


\title{
Adaptive calibration for reduced fuel consumption and emissions
}

\author{
Carlos Guardiola, Benjamín Pla, Pau Bares, and Harald Waschl
}

\begin{abstract}
This paper presents a model based approach to continuously adapt the engine calibration to the traffic and changing pollutant emission limits. The proposed strategy does not need additional experimental tests to that required by the traditional calibration approach. The method relies on information currently available in the ECU to adapt the engine control to the particular driving patterns of a given driver. Additional information about the emissions limits should be provided by an external structure if an adaptation to the pollutant immission is pursued.

The proposed strategy has been implemented in a light-duty diesel engine showing a good potential to keep $\mathrm{NO}_{\mathrm{x}}$ emissions around a defined limit.
\end{abstract}

Index Terms

optimal control; engine calibration

Carlos Guardiola, Benjamín Pla (corresponding author) and Pau Bares are with CMT-Motores Térmicos, Universitat Politècnica de València, Valencia, Spain \{carguaga, benplamo, pabamo\}@mot.upv.es

Harald Waschl is with the Institute for Design and Control of Mechatronical Systems, Johannes Kepler Universität, Linz, Austria \{harald.waschl\}@jku.at. 


\section{Adaptive calibration for reduced fuel consumption and emissions}

\section{INTRODUCTION}

Current engine control concept is based on the use of a static set of maps, which contains the values of the different control actions to be applied. Engine calibration consists in filling the maps contained in the control structure of the engine, i.e. in defining the tuning parameters used by engine control strategies. If those values are properly chosen the engine will fulfil some performing criteria and produce lower emission levels than some established limits during a predefined working cycle (i.e. homologation cycle). Calibration stands a major problem in engine control design, and the number of calibratable parameters reach several tens of thousands [1].

In addition to the calibration burden, the main issue of this approach is that neither the considered engine cycles nor the limits imposed are representative of the real operating conditions of the vehicle [2]-[4]. In this sense, significant efforts are being done for considering more representative cycles [5], but it must be noticed that engine operating cycles differ from one driver to another and from one situation to another (traffic, weather conditions,...). Literature reports the important effects of the driving conditions on engine performance and emissions [6], [7], and there are proposals for changing the certification process to a random cycle from a real-life recorded data set, or to the onboard evaluation through portable emission measurement systems (PEMS) [2], [8]. As a consequence, it may be desirable to include information about the driving patterns in the engine control strategy.

The fact that fixed calibrations are used regardless of the driving conditions also causes the engine not to behave in an optimal way: since the traffic intensity varies significantly depending on the region, air pollution limits are usually exceeded in urban areas with high vehicle densities and traffic intensities, specially during rush hours, while the tight emission limits penalise the fuel consumption and $\mathrm{CO}_{2}$ emissions in those regions where the vehicle densities are low and local pollution is not an issue. Hence it would be advisable to adapt the calibration objectives (i.e. emission limits) to the driving situation and local conditions.

In this sense, the authors showed in a previous paper [9] the potential of considering an immission approach to limit the vehicle pollutant emissions while minimising the fuel consumption and $\mathrm{CO}_{2}$. This approach was based on mapping the engine emissions limits with the vehicle location by considering different immissions hypothesis and data about traffic intensities. Once the emission limits through the route were defined, a control strategy switched between different calibrations in order to meet the emission limits while minimising fuel consumption and $\mathrm{CO}_{2}$ production.

The growth in the availability of environmental information in the vehicle, through geo-localisation, infrastructureto-vehicle (I2V) or vehicle-to-vehicle (V2V) networks [10], [11], may provide key information for the prediction of future driving profile [12], [13] and also assist the driver for fuel and emission efficient driving [14]-[16]. The 
adaptation of the engine calibration to optimise the engine behaviour is possible in this framework but, despite its potential, little information is available in the literature for the moment, see for example [17] and references within.

Under this scope, this paper introduces an online strategy to continuously adapt the engine calibration to the driving conditions, minimising fuel consumption while fulfilling some emission limits. These emission limits may change over time and space, thus considering the possibility of incorporating local stricter regulations in cities or adapting the vehicle emissions to the atmospheric pollutants level. This strategy is based on estimating the future engine operating conditions with past information of its power requirements and then perform an optimisation for a set of different $\mathrm{NO}_{\mathrm{x}}$ production levels. Afterwards, those optimal control actions are transformed in a set of calibrations mapped with the $\mathrm{NO}_{\mathrm{x}}$ emissions. Finally, using a $\mathrm{NO}_{\mathrm{x}}$ sensor [18], [19] or an observer [20], the deviations in emissions respect to a predefined limit are corrected by switching amongst the set of calibrations available.

For the sake of simplicity, the paper will be limited to adapt the steady state calibration of the start of injection $\left(u_{s o i}\right)$, air mass flow and intake pressure set points $\left(M A F_{s p}\right.$ and $\left.M A P_{s p}\right)$ while dynamic factors applied in the standard calibration will be maintained. In the same way, the only pollutant emission considered is $\mathrm{NO}_{\mathrm{x}}$. There are three main reasons for this arbitrary decision. First, control actions leading to low $\mathrm{NO}_{\mathrm{x}}$ emissions (EGR, delayed injection,...), usually involve a penalty on fuel consumption, however, measured taken to reduce fuel consumption usually reduce the formation of pollutant emissions as particulate matter, i.e the tradeoff between fuel consumption and $\mathrm{NO}_{\mathrm{x}}$ is the more clear tradeoff between fuel consumption and any pollutant emission. On the other hand, after-treatment for the rest of pollutants is currently widespread [21], so $\mathrm{NO}_{\mathrm{x}}$ is the main issue in current Diesel engines. Finally, the proposed strategy is model-based and there are many possibilities for the on-board estimation of $\mathrm{NO}_{\mathrm{x}}$ (see for example [20], [22], [23] and references within). In opposition, modelling other pollutant emissions as particulate matter still stands a challenge [1]. In any case, it should be noted that the proposed strategy can be easily upgraded to include any pollutant emissions, or more generally any other criteria, if a model is available.

The paper is organised as follows: section II provides a mathematical formulation of the problem, i.e. adapting the engine calibration to minimise the fuel consumption given certain constraints on $\mathrm{NO}_{\mathrm{x}}$ emissions over an unknown driving cycle. The proposed strategy is detailed in section II, where both the optimisation algorithm and the method to estimate the engine operating conditions are described. Then, section III is devoted to introduce the experimental set up and the model employed for the calibration. In section IV the results obtained with the simulation framework and in the experimental facility are analysed, and finally the most important contributions of the proposed strategy are outlined in section $\mathrm{V}$.

\section{PROBLEM FORMULATION AND PROPOSED STRATEGY}

The problem of engine control may be formally addressed by applying optimal control theory [24]. In this case, the control problem can be defined as finding the control law $u(t)$ over an specific driving run that minimises a cost function containing the fuel consumption. The problem is constrained due to the limitations in the actuators range and restrictions concerning the maximum amount of pollutant emissions allowed over the complete driving 
cycle. One of the main issues of this approach is that it directly produces the control policy to apply in a given driving cycle, but such policy may not be mapped into a calibration because it depends on time. In addition, optimal control approaches are computationally expensive and require an a priori knowledge of the driving cycle, what prevents its application for real-time control.

To overcome these drawbacks, the standard calibration strategy consists on taking a driving cycle, e.g. the New European Driving Cycle (NEDC), or a set of them to make an optimisation and then use the obtained results to fill the calibration maps. However, in this case, the optimality of the calibration for a given driver will depend on the similarity between the NEDC and his driving patterns. In the same way, this approach neglects other boundaries as the traffic, pollution levels in the area or other environmental conditions.

As an intermediate solution between the optimal control approach and the standard static calibration, the present paper poses the calibration problem as finding the group of maps $(\mu=\mu(n, M))$ containing the set points that minimise the accumulated fuel consumption $\left(m_{f}\right)$ over a sequence of engine speeds and torques $(n, M)$ representative of the driving conditions for a specific driver:

$$
\operatorname{argmin}_{\mu \in \mathbb{R}^{N_{\mu}}}\left\{\int_{t_{0}}^{t_{f}} m_{f}(n(t), M(t), x(t), \mu(t)) \mathrm{dt}\right\}
$$

such that:

$$
\int_{t_{0}}^{t_{f}} N O_{x}(n(t), M(t), x(t), \mu(t)) \mathrm{dt} \leq N O_{x}^{l i m}
$$

where $\mu$ represents the different calibrations to be determined (i.e. the values for $u_{s o i}, M A F_{s p}$ and $M A P_{s p}$ ), $N_{\mu}$ is the accumulated size of the maps $(\mu)$ and $x$ is the vector containing the states of the system.

Typically, the turbocharger speed and a set of pressures, temperatures and gas compositions in the intake and exhaust manifolds are taken as system states. However, to some extent, the engine behaviour may be approximated through a quasi-steady representation [25], [26] where the engine performance, consumption and emissions are mapped as a function of engine speed and load. Such approach, which is usually used for hybrid electric vehicle (HEV) supervisory control, has demonstrated to be a sufficient approximation for fuel consumption and $\mathrm{NO}_{\mathrm{x}}$ prediction [27], [28]; once again including additional pollutants would be a challenge, because quasi-steady modelling may provide significantly biased predictions [27].

\section{A. Proposed strategy}

Neglecting the system dynamics by assuming quasi-steady behaviour, the problem posed in equations (1) and (2) may be strongly simplified. In fact, the constrained dynamic minimisation is converted into a static optimisation problem that can be addressed by the method of Lagrange multipliers. Instead of an integral problem consisting of minimising the fuel consumption $\left(m_{f}\right)$ with respect to the applied calibration $(\mu)$ with constraints on the maximum $\mathrm{NO}_{\mathrm{x}}$ emissions, the problem is simplified to the instantaneous minimisation of a cost function $F$, defined as:

$$
F=m_{f}(n, M, \mu)+\lambda N O_{x}(n, M, \mu)
$$


where the Lagrange multiplier $\lambda$ should be chosen to fulfil the $\mathrm{NO}_{\mathrm{x}}$ emission constraint (2) at the end of the cycle. Note that the $\lambda$ parameter weights the importance of $m_{f}$ and $\mathrm{NO}_{\mathrm{x}}$ in the cost function. Particularly, if $\lambda=0$ the cost function only takes into account the fuel and the optimisation will lead to control action minimising the fuel injection without considering any penalty in the $\mathrm{NO}_{\mathrm{x}}$ emissions. On the contrary, at the limit of $\lambda$ tending to $\infty$ the $\mathrm{NO}_{\mathrm{x}}$ will be minimised with negligible penalty on fuel consumption. The introduction of other constraints (other emissions or noise) would involve the consideration of additional Lagrange multipliers.

If the value of the Lagrange multiplier is known, and there are models for the prediction of $m_{f}$ and $\mathrm{NO}_{\mathrm{x}}$, the optimal calibration may be solved:

$$
\mu^{*}(\lambda)=\operatorname{argmin}_{\mu \in \mathbb{R}^{N_{\mu}}}\{F(n, M, \mu, \lambda)\}
$$

$\mu^{*}$ stands for the optimal calibration maps that minimise expression (3) for a given value of $\lambda$. Note that $\mu$ intrinsically depends on the considered operation point, i.e. $\mu$ is a set of matrices scheduled with $n$ and $M$.

Furthermore, optimal fuel consumption and emissions may also be computed:

$$
\begin{aligned}
& m_{f}^{*}(n, M, \lambda)=m_{f}\left(n, M, \mu^{*}(\lambda)\right) \\
& N O_{x}^{*}(n, M, \lambda)=N O_{x}\left(n, M, \mu^{*}(\lambda)\right)
\end{aligned}
$$

The optimal fuel consumption and emissions depend on the considered $\lambda$, which defines the associated optima calibration $\mu^{*}$. It must be highlighted that the optimal values $\mu^{*}, m_{f}^{*}$ and $N O_{x}^{*}$ may be computed offline upon the existence of the needed prediction models (but may also be performed online if prediction models are updated [22], [29]).

The problem is then reduced to find the optimal value of $\lambda$ that is able to solve the problem (1)-(2). The integrated fuel and emissions could be straightforward computed when the cycle is known:

$$
\begin{aligned}
& s m_{f}^{*}=\frac{1}{\bar{v}} \sum_{i=1}^{k} m_{f}^{*}(n(k), M(k), \lambda) \\
& s N O_{x}^{*}=\frac{1}{\bar{v}} \sum_{i=1}^{k} N O_{x}^{*}(n(k), M(k), \lambda)
\end{aligned}
$$

where the cycle has been approximated through a sequence of $k$ independent engine speeds and demanded torques, and the cycle averaged speed $\bar{v}$ is used for converting from rate (e.g. g/s) to specific consumption and emissions (typically in $\mathrm{gkm}^{-1}$ ).

The usual calibration process is based on the calculation over a known cycle. In opposition, the present paper proposes to store the engine speed and torque demands in order to modify the engine calibration according to the driving patterns and some limits on emissions that vary depending on the vehicle location and other boundary conditions. The method is based on estimating future driving power requirements $(n, M)$ in a stochastic fashion and then applying the Lagrange multiplier $(\bar{\lambda})$ which fulfils the $\mathrm{NO}_{\mathrm{x}}$ restriction in an averaged sense. The value of $\bar{\lambda}$ is found by solving the equation: 


$$
\mathbf{E}\left\{s N O_{x}^{*}(n, M, \bar{\lambda})\right\}=s N O_{x}^{\lim }
$$

where $\mathrm{sNO}_{x}^{\text {lim }}$ refers to the allowed $\mathrm{NO}_{\mathrm{x}}$ emissions in $\mathrm{gkm}^{-1}$ and $\mathbf{E}\left\{s N O_{x}\right\}$ denotes the expected $\mathrm{NO}_{x}$ emissions in $\mathrm{gkm}^{-1}$, which depends on the operating conditions considered $(n, M)$ and the $\lambda$ parameter used to fix the calibration $\mu$ through the minimisation of the cost function $F$ (3).

For a particular driver, the probability of any combination $n-M$ can be estimated from the frequencies observed during a given sliding window. Similarly, the averaged vehicle speed $(\bar{v})$ can be obtained from the history of the vehicle. In this sense, the expected value of the $\mathrm{NO}_{\mathrm{x}}$ emissions in $\mathrm{gkm}^{-1}$ can be calculated as:

$$
\mathbf{E}\left\{s N O_{x}^{*}\right\}=\sum_{i=1}^{N_{n}} \sum_{j=1}^{N_{M}} \mathbf{P} r\left(n_{i}, M_{j}\right) \frac{N O_{x}^{*}\left(n_{i}, M_{j}, \lambda\right)}{\bar{v}}
$$

where $n_{i}$ and $M_{j}$ are any of the possible $N_{n}$ values of engine speed and $N_{M}$ values of demanded torque respectively, and $\mathbf{P} r$ stands for the probability matrix that represents the driving pattern.

Note that $\mathbf{E}\left\{s N O_{x}^{*}\right\}$ will depend on the selection of $\lambda$. Upper plot in Figure 1 shows, for a given driving pattern expressed through its probability matrix $\mathbf{P} r$, the expected $\mathrm{NO}_{\mathrm{x}}$ emissions for different values of the Lagrange multiplier, while the lower plot shows the expected fuel consumption. Note that independently on the driving pattern, equation 3 involves a monotonic increase of fuel consumption and reduction of $\mathrm{NO}_{\mathrm{x}}$ with increasing $\lambda$. For the particular driving pattern considered in this paper, results point out that taking into account the limits in the control parameters of Table II, the driver of the study will produce $0.77 \mathrm{~g} / \mathrm{km}$ of $\mathrm{NO}_{\mathrm{x}}$ if no $\mathrm{NO}_{\mathrm{x}}$ penalties were considered $(\lambda=0)$, this value can be reduced to less than $0.3 \mathrm{~g} / \mathrm{km}$ by including a penalty on the $\mathrm{NO}_{\mathrm{x}}$ emissions $(\lambda=75)$. Of course, this reduction in the $\mathrm{NO}_{\mathrm{x}}$ emissions involves an increase in fuel consumption, in this case around a $10 \% \cdot \bar{\lambda}$ is straightforward determined just equalling the expected $\mathrm{NO}_{\mathrm{x}}$ emissions to the limit specified.

Note that for any expected value of $\mathrm{NO}_{\mathrm{x}}$ emissions, the control actions produced by its corresponding $\bar{\lambda}$ value lead to the fuel consumption minimisation in the set of considered operating conditions $(n, M)$ and they can be stored in calibration maps. Then, the proposed method supplies a complete calibration of the selected control parameters that allows the driver to minimise the fuel consumption with a bounded expected NOx production. Figure 2 shows the look-up tables obtained for the extreme cases, i.e. minimum fuel consumption $(\bar{\lambda}=0)$ and minimum $\mathrm{NO}_{\mathrm{x}}$ emissions $(\bar{\lambda}=75)$. According to that results, the calibration aimed to reduce NOx emissions involve later injection processes and lower air mass flows, while the calibration whose objective is to reduce fuel consumption, leads to earlier fuel injections and higher air mass flows. Moreover, it can be observed that with $\bar{\lambda}=75$, the intake pressure is higher in a wide area of the operating map, since higher intake pressures with lower air mass flows involve higher EGR rates, then leading to lower $\mathrm{NO}_{\mathrm{x}}$ emissions (at the expense of higher pumping losses).

Figure 3 summarises the proposed methodology. As it has been described, there are three steps in the process:

1) Solving the optimal calibration for every possible value of the scheduling Lagrange multiplier $\lambda$.

2) Computing, according to the driving pattern, the expected $\mathrm{NO}_{\mathrm{x}}$ emissions and fuel consumption, that will be again a function of $\lambda$. 

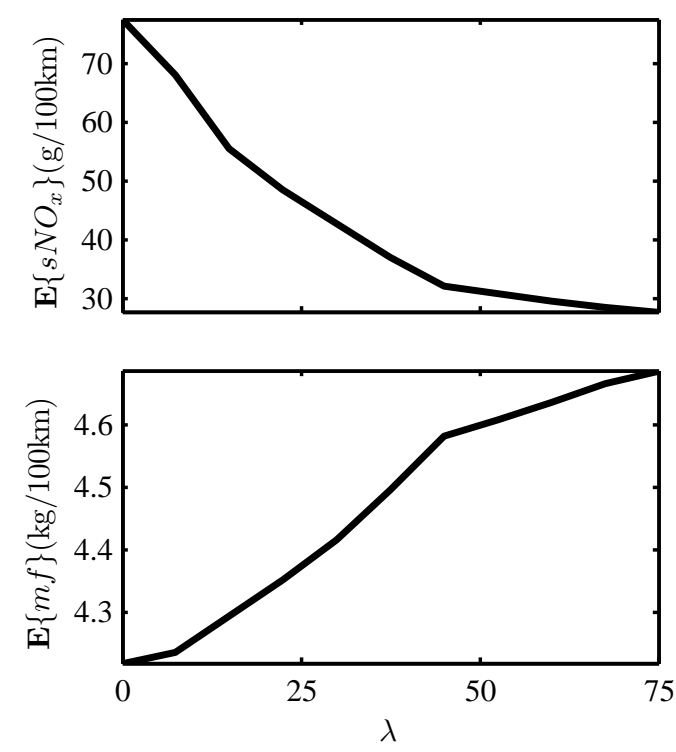

Fig. 1. Expected $\mathrm{NO}_{\mathrm{x}}$ emissions and fuel consumption depending on the value of the parameter $\lambda$ for the particular probability distribution and averaged vehicle speed shown in Figure 4

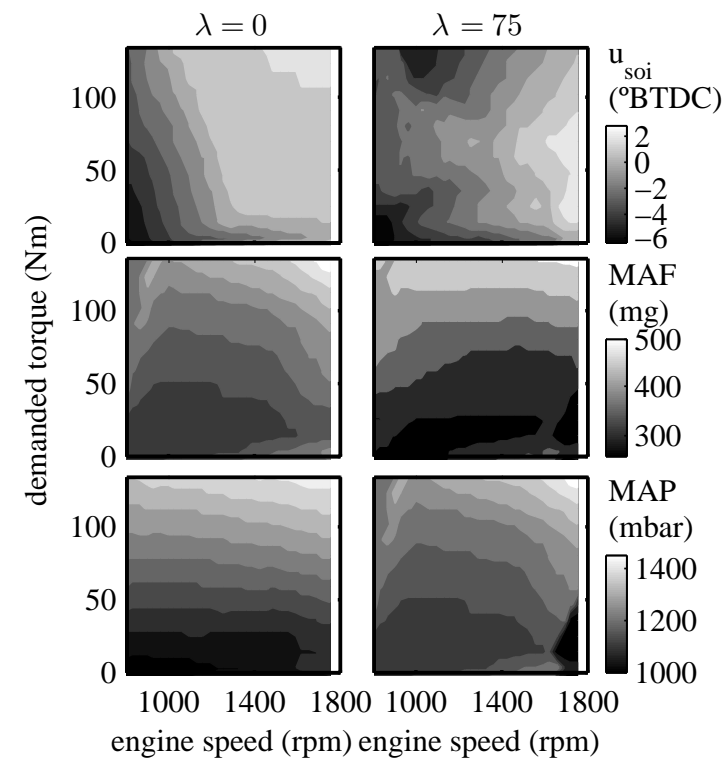

Fig. 2. Calibration maps obtained for $u_{\text {soi }}$ (top), MAF (center), and MAP (bottom), with $\bar{\lambda}=0$ (minimum fuel consumption) and $\bar{\lambda}=75$ (maximum $\mathrm{NO}_{\mathrm{x}}$ reduction). 
3) Calculating $\bar{\lambda}$ for satisfying a given emission limit.

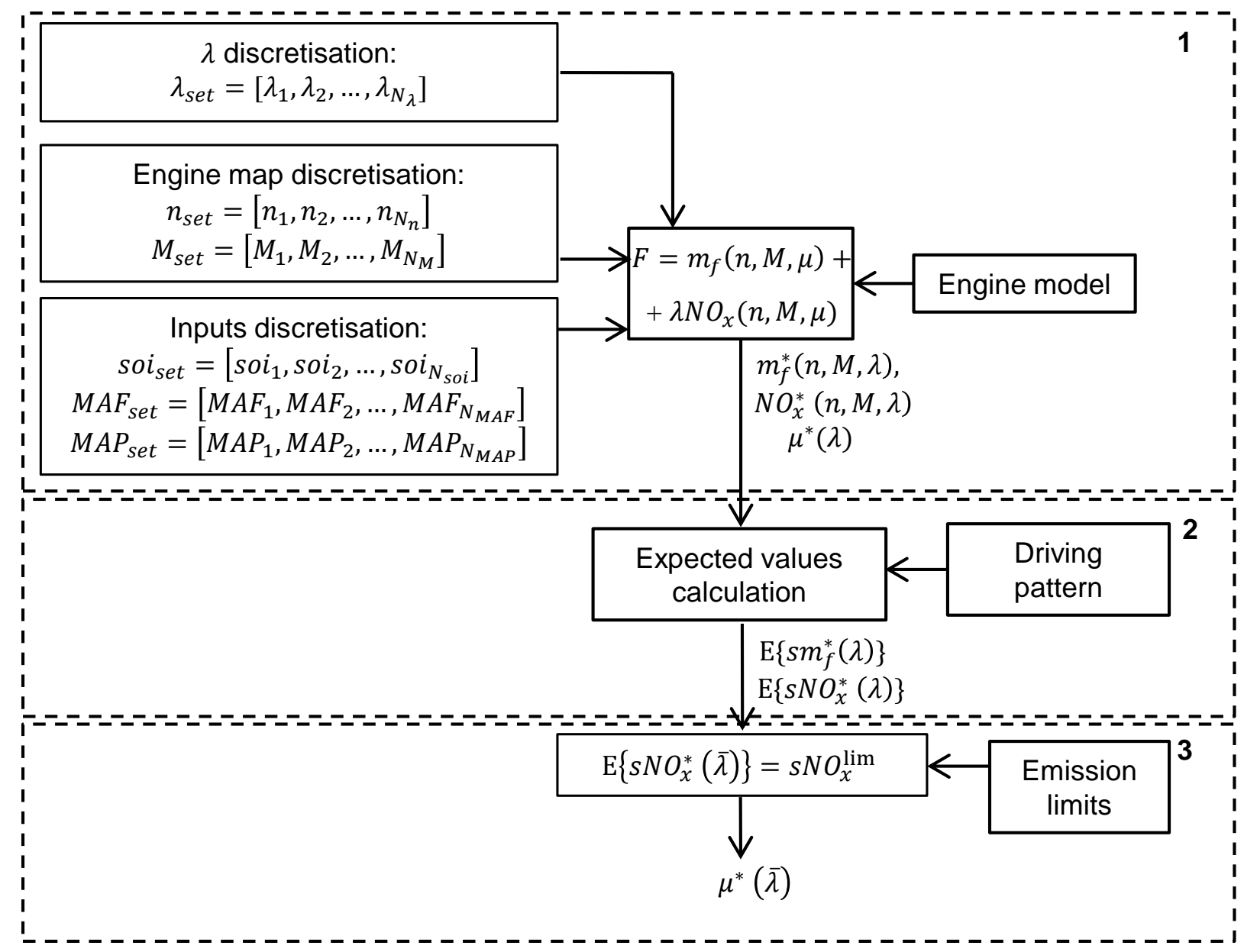

Fig. 3. Diagram showing the proposed methodology to adapt the engine calibration to the driver style and the $\mathrm{NO}_{\mathrm{x}}$ limit

Note that, for fixed engine model, driving pattern and emission limits, the three steps may be performed offline. However, different benefits may be obtained if they are solved online: if step 3 is performed online, the calibration may consider time-varying emission limits; if step 2 is performed online, the calibration may be adapted to varying driving patterns; finally, solving step 1 online would allow to tune the calibration to an adaptive engine model. The present paper will exclusively concentrate on the adaptation to the driving pattern and emission limits.

\section{MATERIALS AND METHODS}

Two main elements are required for applying the proposed methodology: on the one hand information about the conditions in which the engine operates regularly, in order to estimate the future engine operating conditions; on the other hand, a model able to predict the fuel consumption and $\mathrm{NO}_{\mathrm{x}}$ emissions. Furthermore, taking into account that both the prediction about the operating conditions and the model are subjected to significant uncertainties, some feedback control will be necessary in a real-life application. 


\section{A. Experimental setup}

In order to identify the engine model, to carry out the calibration and to validate the proposed control strategy a dynamic test bench with the turbocharged Diesel engine, whose main characteristics appear in Table I, has been used.

\begin{tabular}{ll}
\hline Type & Common-Rail-DI \\
Air path & EGR-Sequential parallel turbo [30] \\
Number of cylinders & 4 \\
Displacement & $2179 \mathrm{~cm}^{3}$ \\
Maximum power & $125 \mathrm{~kW} \mathrm{@} \mathrm{4000} \mathrm{rpm}$ \\
Compression ratio & $17: 1$ \\
\hline
\end{tabular}

ENGINE MAIN CHARACTERISTICS.

For the measurement of the exhaust gas composition $\left(\mathrm{O}_{2}, \mathrm{CO}_{2}, \mathrm{CO}, \mathrm{HC}\right.$ and $\left.\mathrm{NO}_{\mathrm{x}}\right)$ an exhaust gas analyser Horiba MEXA 7100 DEGR was used. Particularly, regarding the online calibration approach a $\mathrm{ZrO}_{2} \mathrm{NO}_{\mathrm{x}}$ sensor was also employed.

The engine is equipped with a development ECU with a bypass system and thus it is possible to directly access parts of the control unit, e.g. the desired setpoints of the MAP and MAF, or the $u_{s o i}$. To implement the proposed strategy and record the measurement data a PXI prototyping system was used, it was connected via CAN interface with the ECU and with other measuring devices. Also, the proposed strategy was implemented in the PXI so, by means of using the instantaneous demands on engine speed and torque and the signal provided by the $N O_{x}$ sensor, the ECU maps for $M A P_{s p}, M A F_{s p}$ and $u_{s o i}$ were bypassed. The ECU allowed real time bypass via an ETK protocol, so numerical values for $\mathrm{u}_{S O I}, \mathrm{MAF}_{s p}$ and $\mathrm{MAP}_{s p}$ may be externally imposed, and ECU measurements made available to external systems. Since bypass was used for MAP and MAF at the set-point layer, low-level controllers for the VGT and EGR were the ECU originals. Then, while the ECU static MAF and MAP setpoints are bypassed, the rest of the original engine calibration has been maintained so those static set points are corrected with factors that take into account dynamic effects (smoke limiter,...) and deal with special engine operation modes such as idle or DPF regeneration. As hardware configuration for the present work, an ETAS ES910 system was used together with a National Instruments Real Time PXI: control logics were programmed in the PXI, which also allowed the integration of external sensors as the NOx sensor; the ES910 hardware was connected to the PXI via CAN and to the ECU via ETK, just acting as bridge between the PXI and the ECU.

A detailed description of the methodology and the conducted experiments that lead to the model calibration is given in section III-C. Meanwhile, a set of driving cycles from those obtained from real driving conditions as outlined in III-B where carried out to validate the adaptive calibration method. 


\section{B. Driving information}

Although future driving conditions are unknown, a personalised estimation for any driver is proposed based on past information about his driving patterns. In this sense, real world data was collected during a testing campaign of three weeks in which every car trip of a non professional driver was recorded. Measurements were done in Valencia during October 2011 with a compact car. During the test campaign a total distance of $150 \mathrm{~km}$ was covered in urban conditions with a mean velocity of $18.9 \mathrm{kmh}^{-1}$.

In the test campaign, a GPS recording system was used and ECU readings were acceded to measure the vehicle velocity and engine parameters, mainly engine speed and torque. The operating points in the engine map are represented in Figure 4. The colorscale in the upper plot shows the frequency of the operating conditions ranging from light grey (low probability) to dark grey (high probability). The proposed method is based on a forward extrapolation of the probabilities of the possible combinations of engine speed and torque achieved during a given sliding window. In particular, the probability matrix of Figure 4 is computed by analysing the frequency at which the engine has passed through different operating points defined by engine speed and demanded torque during a receding horizon (in the case at hand $150 \mathrm{~km}$ ). Assuming that the driving pattern followed by the driver is going to be the same in the next future, the probability of a given engine condition can be assumed to be equal to the frequency observed during the receding horizon.

The lower plot in Figure 4 shows the averaged vehicle speed throughout the engine operating range. The vehicle speed is a valuable information to pass from $\mathrm{NO}_{\mathrm{x}}$ emissions in $\mathrm{gh}^{-1}$ to $\mathrm{gkm}^{-1}$, which seems to be more appropriated from the point of view of pollutant regulations. Note, that in a real-time application, both maps (frequencies and averaged vehicle speeds) may be continuously updated since the information used is completely accessible in a state-of-the-art ECU.

Previous maps show that the engine operates frequently in the low load and speed range, which is common in urban driving. In the same sense, the vehicle speed ranges from 0 to $70 \mathrm{kmh}^{-1}$, which is also usual at those conditions. Even more, Figure 4 points out that high load operating conditions are infrequent and a reduced impact of the calibration at those conditions is expected. Similarly, for a given emissions level (in $g s^{-1}$ ) operating conditions with high averaged velocities are expected to have a lower influence in the $\mathrm{NO}_{\mathrm{x}}$ emissions (in $\mathrm{gkm}^{-1}$ ). This highlights the importance of a suitable calibration at low speed and load conditions is highlighted.

\section{Quasi-steady approach}

Non-causal models are usually employed in powertrain simulation because of its acceptable accuracy with low computational cost [25]. With this approach, the power at the powertrain elements is tracked backwards, starting from the mechanical power at the wheels, which is determined applying an energy balance to the vehicle, given its inertial, rolling and aerodynamic characteristics and the speed and road profiles. The non-causality of the model involves that the driving cycle will be perfectly followed, which makes the comparison between different control strategies easier but also makes results senseless if powertrain elements are not properly sized. To track the power 


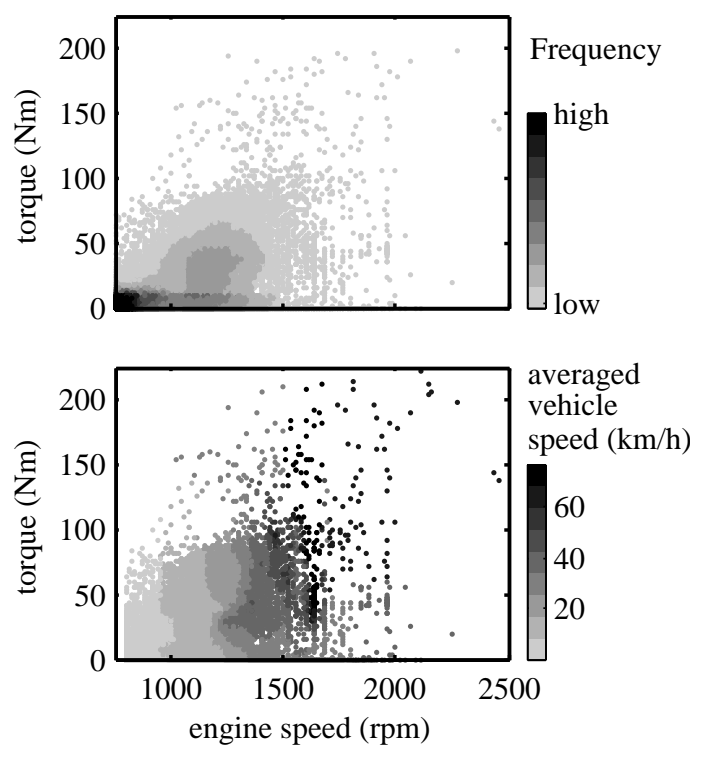

Fig. 4. Operating points in the engine speed vs torque map. The upper plot represents the frequency of the operating points in the recorded driving conditions. The lower plot shows the averaged vehicle speed at the recorded driving conditions.

along the driveline elements, their efficiency is mapped with speed and torque, while limitations in torque are also introduced with speed.

The functions to calculate the engine fuel consumption and $\mathrm{NO}_{\mathrm{x}}$ emissions take into account engine speed and demanded torque, but also other inputs. The selected engine controls are the start of injection $\left(u_{\text {soi }}\right)$, the EGR and VGT actuation signals $\left(u_{e g r}\right.$ and $\left.u_{v g t}\right)$. Nevertheless, while $u_{\text {soi }}$ has been selected as a model input, the other two signals have been substituted by the air mass flow $(M A F)$ and the intake pressure $(M A P)$, and the VGT and EGR valve are supposed to follow the policy able to track the $M A F$ and $M A P$ set points ( $M A F_{s p}$ and $\left.M A P_{s p}\right)$. Moreover, assuming the quasi-steady behaviour, the actual $M A F$ and $M A P$ can be approximated by their respective reference values $M A F_{s p}$ and $M A P_{s p}$. In this sense, quadratic models for $\mathrm{NO}_{\mathrm{x}}$, and fuel consumption depending on engine speed, demanded torque, $u_{\text {soi }}, M A F$ and $M A P$ are proposed, where the model parameters are to be determined from experimental data according to the Least Squares Method. Particularly, a set of 21 nodes defined by engine speed and demanded torque covering the complete engine map were chosen. Then, at any node a local model for NOx and fuel consumption consisting of second order polynomials were identified. The local models were quadratic expressions depending on $M A F, M A P$ and $u_{\text {soi }}$ with the following structure:

$$
\begin{aligned}
& y=\beta_{0}+\beta_{1} M A F+\beta_{2} M A F^{2}+\beta_{3} M A P+ \\
& \quad+\beta_{4} M A P^{2}+\beta_{5} u_{\text {soi }}+\beta_{6} u_{\text {soi }}^{2}+\beta_{7} M A F M A P+ \\
& +\beta_{8} M A F u_{\text {soi }}+\beta_{9} M A P u_{\text {soi }}
\end{aligned}
$$


where $y$ is the model output $\left(m_{f}\right.$ or $\left.\mathrm{NO}_{\mathrm{x}}\right)$ and coefficients $\beta$ were obtained by minimisation of the square error between the model output $(y)$ and the corresponding measured signal during experiments. Finally, the output of the global model is computed by linear interpolation (Triangulation-based linear interpolation)between the local models results around the operating condition $(n-M)$. Other kind of models available in the literature, for instance radial basis functions (RBF), [31]-[33], can be used if the quadratic models do not produce suitable results.

To identify the engine model, a set of 21 operating conditions, sweeping the operating area found during drivings tests explained in section III-B, was selected. For each of the 21 operating conditions, 36 combinations of $u_{\text {soi }}$, $M A F$ and $M A P$ obtained from a D-Optimal Design of Experiment are tested in order to fit local models for $\mathrm{NO}_{\mathrm{x}}$ and fuel consumption. Regarding the variation intervals for the model inputs, choosing a suitable range of allowed variations in the control parameters is a task of major concern since it will determine the complexity of the models to use, and therefore the number of tests to be carried out. Allowing control parameters to vary in a wide range involves obtaining highly non-linear responses which should be modelled with high order models requiring a large number of tests. On the other side, setting too restrictive ranges of variation may limit the effect of the calibration changes on engine performance. In the case of the $u_{s o i}$ range, it is mainly limited by peak cylinder pressure, efficiency and $\mathrm{NO}_{\mathrm{x}}$. Late injections (negative values) lead to late combustion, involving low peak cylinder pressures and then low engine efficiency. As the injection is advanced (high $u_{s o i}$ ), the combustion is progressively centred increasing engine efficiency but also $\mathrm{NO}_{\mathrm{x}}$ emissions. Finally too early injections deteriorate fuel efficiency due to a bad combustion phasing or even produce excessive pressure gradients in the combustion chamber that may harm the engine. In the case of $M A F$ and $M A P$, limits are imposed by excessive fuel-to-air ratios and EGR rates that lead to excessive fuel consumption and soot emissions. In addition, the variations in all the model inputs ( $u_{\text {soi }} M A F$ and $M A P$ ) should be limited to the range in which simple polynomial models work properly. Table II contains the ranges used in the present study for the three variables; in all cases local variations around production values (marked with subscript $o$ ) have been used.

\begin{tabular}{c|cc}
\hline Variable & minimum & maximum \\
\hline$u_{\text {soi }}$ & $u_{\text {soi }, o}-3 \mathrm{deg}$ & $u_{\text {soi }, o}+3 \mathrm{deg}$ \\
$M A F$ & $0.85 M A F_{o}$ & $1.15 M A F_{o}$ \\
$M A P$ & $M A P_{o}-50$ mbar & $M A P_{o}+50$ mbar \\
\hline
\end{tabular}

TABLE II

RANGE OF VARIATION FOR THE MODEL INPUTS DURING THE IDENTIFICATION TESTS.

Note that the experimental cost of the proposed method is similar to that of the standard calibration approach.

Figure 5 shows an example of the identification tests, where the engine speed and torque is kept constant $(\mathrm{n}=2500$ rpm \& $\mathrm{M}=150 \mathrm{Nm}$ ), variations in the model inputs (i.e. $u_{\text {soi }}, M A F$ and $M A P$ ) are continuously applied and the fuel mass is left as a free parameter able to change in order to keep the desired torque. 

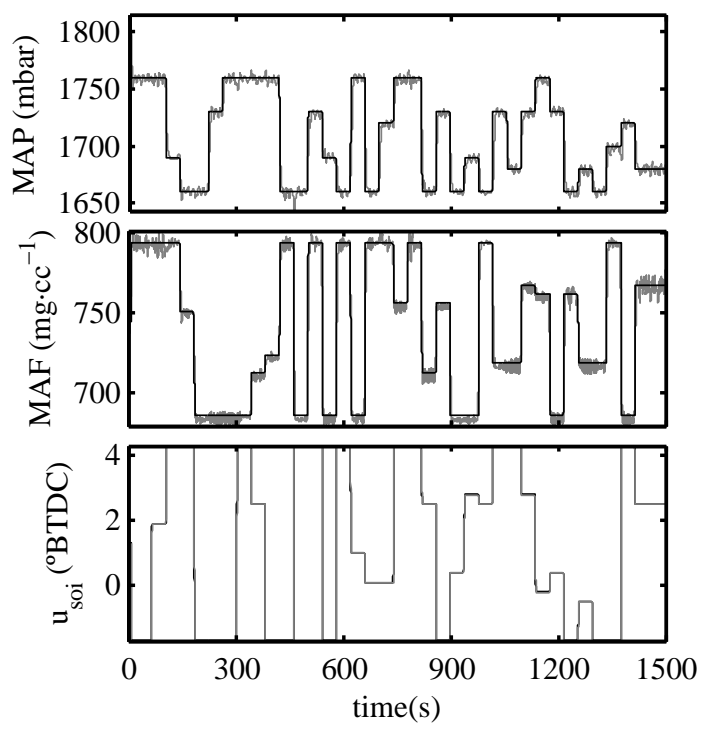

Fig. 5. Identification test at operating conditions \#21 $(\mathrm{n}=2500 \mathrm{rpm} \& \mathrm{~T}=150 \mathrm{Nm})$. Black lines represent the set point evolution and grey lines represent actual values.

The results of that kind of test are shown in Figure 6. It can be observed how the quadratic models identified (grey lines) are able to follow the measured fuel mass flow and $\mathrm{NO}_{\mathrm{x}}$ emissions signals (black lines). Some noise appears in the model results due to the propagation of the noise in the model input signals.

Repeating that sort of test for the rest of operating conditions, a set of local models can be constructed. The set of operating conditions (nodes), where the local models are identified, and the comparison between measurements and model results appear in Figure 7. A good agreement between measured and the results of the local models can be observed at static conditions. Once the local models are identified, the global model output in a given operating condition is defined as a linear combination of the nearest nodes [34].

In order to validate the model a dynamic test representing the NEDC has been carried out in the engine test bench. Figure 8 shows a comparison between the measured (black line) and model (grey line) results. It can be observed that the model results agree with measurements even though the simple model used and the quasi-steady hypothesis. However, it must be admitted that such simplistic models would produce important errors if other pollutants as particulate matter or HCs were addressed.

The difference between the measured and modelled accumulated fuel consumption at the end of the cycle is lower than $0.5 \%$ while the difference in $\mathrm{NO}_{\mathrm{x}}$ emissions rises to the $8 \%$. Therefore, some feedback in the control algorithm is needed to compensate for the $\mathrm{NO}_{\mathrm{x}}$ model uncertainties.

\section{Feedback implementation for online application}

There are two main issues that suggest the convenience of using a feedback control: on one hand, there are unavoidable modelling errors, which may be significant due to the simplistic model structure; on the other hand, 

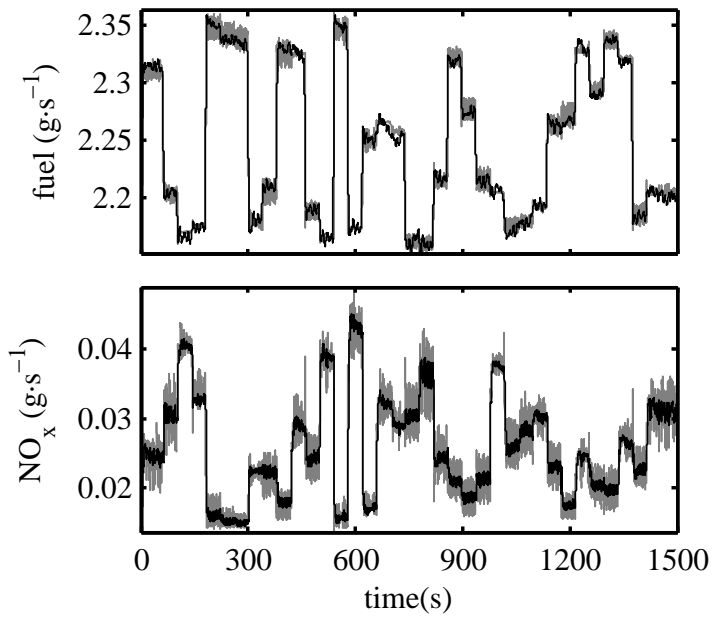

Fig. 6. Identification test at operating conditions \#21 ( $\mathrm{n}=2500 \mathrm{rpm} \& \mathrm{~T}=150 \mathrm{Nm})$. Black lines represent the evolution of the measured fuel and $\mathrm{NO}_{\mathrm{x}}$ emissions while grey lines represent identified model values.

the probability and average speed matrices cannot be properly updated when important changes in driving conditions appear. Both aspects lead to bias in the final predicted $\mathrm{NO}_{\mathrm{x}}$ emissions.

In the present paper a feedback control is proposed in order to reduce the impact of modelling uncertainties and errors in the estimation of the operating conditions: a set point for $\mathrm{NO}_{\mathrm{x}}$ emissions $\left(s N O_{x}^{s p}\right)$ will be defined taking into account the $\mathrm{sNO}_{\mathrm{x}}$ limit and the difference between the desired and the real emissions determined with a sensor or observer within a given time interval. Accordingly, at the time instant $k$ the $\mathrm{NO}_{\mathrm{x}}$ set point is calculated as:

$$
s N O_{x}^{s p, k}=s N O_{x}^{l i m, k}-\left(s N O_{x}^{k-1}-s N O_{x}^{l i m, k-1}\right)
$$

Entering the map presented in the upper plot of Figure 1 with the calculated $\mathrm{NO}_{\mathrm{x}}$ set point, the optimal Lagrange multiplier $\bar{\lambda}$ can be obtained. Each $\bar{\lambda}$ value has a corresponding set of $u_{s o i}, M A F_{s p}$ and $M A P_{s p}$ maps to be applied until the next updating. It is convenient to update the calibrations as frequently as possible in order to track the optimal solution. In fact, the proposed method tends to the optimal control approach as the updating time is reduced, however, a continuous update has an unaffordable computational cost.

\section{Results}

\section{A. Simulation Results}

The performance of the proposed method has been evaluated in real driving conditions by means of its application to a set of cycles performed by the analysed driver. In a first step the method is evaluated by modelling.

Figure 9 shows the results obtained during a simulation of $80 \mathrm{~km}$ of urban driving. In this simulation, different emission limits have been imposed to the same driving cycle. The $\mathrm{NO}_{\mathrm{x}}$ emissions in $\mathrm{g} / \mathrm{km}$ are computed from the start of the cycle and $\lambda$ varies continuously to make up for the deviations from the $N O_{x}$ limit. Each 10 seconds the calibration maps are modified according to the corresponding $\lambda$ parameter. This arbitrary value of 10 seconds 

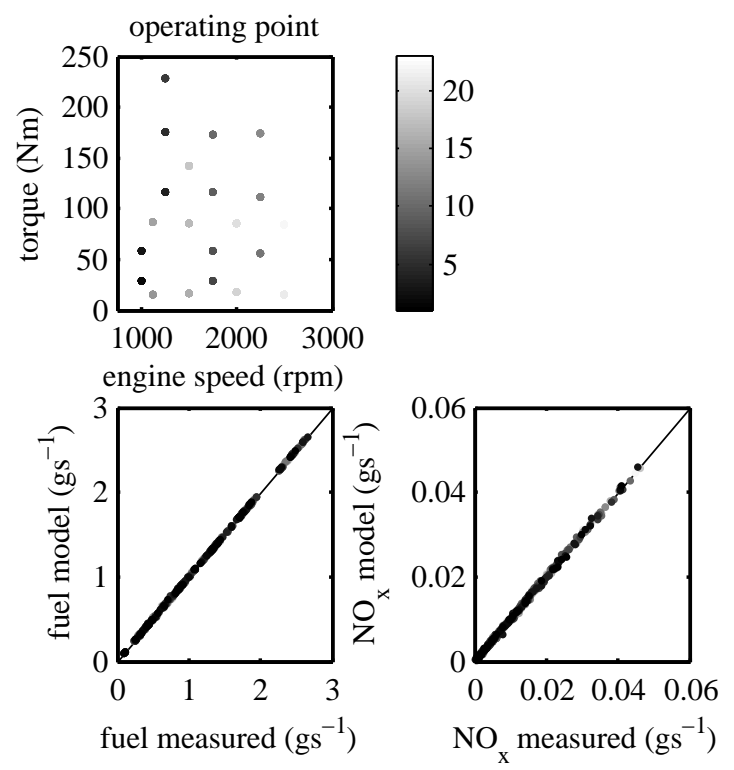

Fig. 7. Operating points used to identify the engine model and comparison between measured and identified fuel consumption and $N O_{x}$ emissions. The colorscale shows the test point.
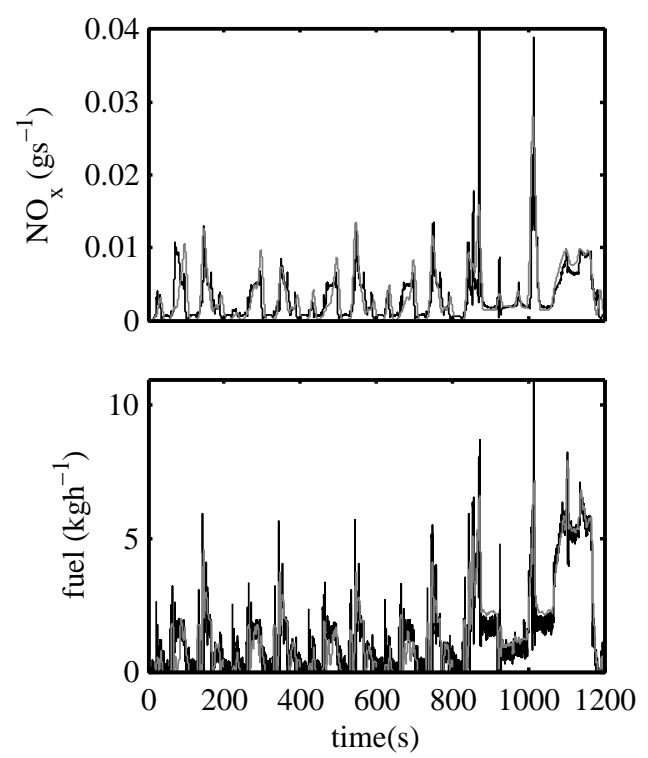

Fig. 8. Comparison between measured (grey) and modelled (black) fuel consumption and $N O_{x}$ emissions during the NEDC. 
has been chosen because is enough time for a real time application. Looking at the figure, it is evidenced that tests with harder $\mathrm{NO}_{\mathrm{x}}$ restrictions involve higher $\lambda$ values, and also, for a given simulation, the $\lambda$ parameter rises as the $\mathrm{NO}_{\mathrm{x}}$ emission increase. At the beginning of the simulation important variations in the $\mathrm{NO}_{\mathrm{x}}$ emissions per $\mathrm{km}$ are observed, which are explained by the phases where the vehicle is stopped and the engine is in idle. As the cycle evolves, the impact of those phases is progressively diluted and the $\mathrm{NO}_{\mathrm{x}}$ emissions tend gradually to the set point. It can be also noticed from the simulation results that a reduction in $\mathrm{NO}_{\mathrm{x}}$ emissions from $0.5 \mathrm{~g} / \mathrm{km}$ to $0.4 \mathrm{~g} / \mathrm{km}$ involves an increase of a $1.5 \%$ in the fuel consumption. Conversely, if the $\mathrm{NO}_{\mathrm{x}}$ restriction is relaxed to $0.6 \mathrm{~g} / \mathrm{km}$ a $1 \%$ fuel saving can be obtained.

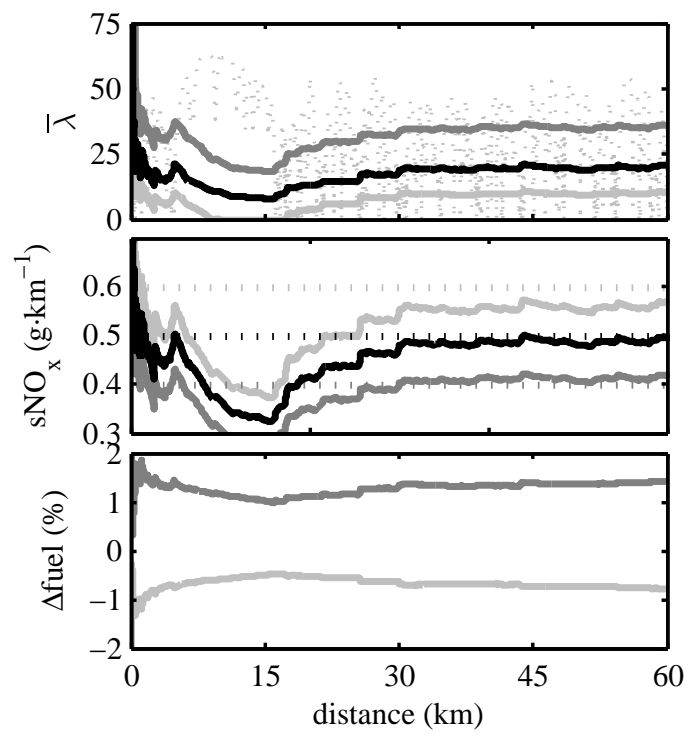

Fig. 9. Simulation results showing the evolution of the applied $\lambda$ parameter (upper plot), $\mathrm{NO}_{\mathrm{x}}$ emissions (medium plot) and difference in fuel consumption (lower plot) amongst tests with different $\mathrm{NO}_{\mathrm{x}}$ objectives: $0.5 \mathrm{~g} / \mathrm{km}$ (reference, black line), $0.4 \mathrm{~g} / \mathrm{km}(\mathrm{dark}$ grey line) and $0.6 \mathrm{~g} / \mathrm{km}$ (light grey line).

In a potential future application, $\mathrm{NO}_{\mathrm{x}}$ limits might change with the vehicle location in order to take into account the local pollutant immission levels (e.g. in urban areas during high polluted days). Figure 10 shows how the method is able to adapt the engine calibration to fulfil with modifications in the emission requirements. In this case, the driving cycle is divided in two different areas. While the first area has a common $\mathrm{NO}_{\mathrm{x}}$ limit of $0.5 \mathrm{~g} / \mathrm{km}$ for the three simulations, the limit in area \#2 has been modified so the calibration is adapted to keep the desired $\mathrm{NO}_{\mathrm{x}}$ level. Obviously, a reduction of $0.1 \mathrm{~g} / \mathrm{km}$ of $\mathrm{NO}_{\mathrm{x}}$ emissions in the zone $\# 2$ has a penalty in fuel consumption of $1.5 \%$, while the increase of the $\mathrm{NO}_{\mathrm{x}}$ limit in $0.1 \mathrm{~g} / \mathrm{km}$ involves a fuel saving of $1 \%$ (note that the values are equivalent as those observed in Figure 9). 


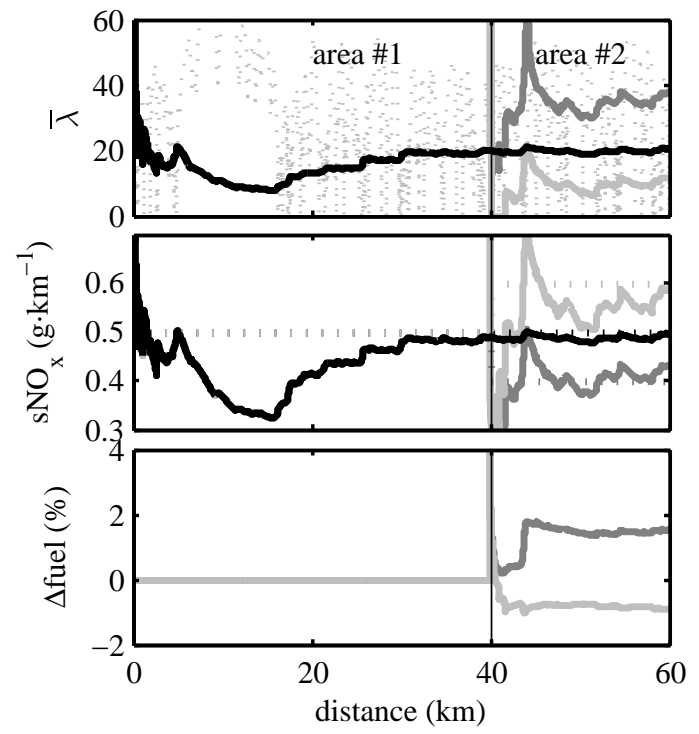

Fig. 10. Simulation results showing the evolution of the applied $\lambda$ parameter (upper plot), $\mathrm{NO}_{\mathrm{x}}$ emissions (medium plot) and difference in fuel consumption (lower plot) amongst tests with different $\mathrm{NO}_{\mathrm{x}}$ objectives in different areas: $0.5 \mathrm{~g} / \mathrm{km}$ (reference, black line), $0.4 \mathrm{~g} / \mathrm{km}$ in area \#2 (dark grey line) and $0.6 \mathrm{~g} / \mathrm{km}$ in area \#2 (light grey line).

\section{B. Experimental Results}

To conclude, the proposed strategy is experimentally evaluated over a real driving cycle. In a first study, the standard calibration is compared with the proposed strategy. The $\mathrm{NO}_{\mathrm{x}}$ emissions during the tested cycle with the standard engine strategy are represented by the black line in the central plot of Figure 11. It can be observed that the standard engine calibration produces around $0.64 \mathrm{~g} / \mathrm{km}$ of $\mathrm{NO}_{\mathrm{x}}$ during the presented driving cycle. Note that those emissions are far from the current $\mathrm{NO}_{\mathrm{x}}$ level that regulation establishes for Diesel engines $(0.18 \mathrm{~g} / \mathrm{km}$ in Euro 6). The reason for this deviation is twofold: on the one hand, the considered engine is a Euro 3 engine, then the $\mathrm{NO}_{\mathrm{x}}$ limit was $0.5 \mathrm{~g} / \mathrm{km}$. On the other hand, the driving cycle considered is noticeably different from the NEDC, which leads to important discrepancies in the engine performance obtained and particularly in emissions.

In order to assess the potential of the proposed strategy Figure 11 compares the results obtained with the standard calibration with those obtained with the adaptive calibration taking a $\mathrm{NO}_{\mathrm{x}}$ target of $0.6 \mathrm{~g} / \mathrm{km}$. The probability and averaged velocity matrices shown in Figure 4 have been used for the adaptive calibration strategy. Neither the probability nor the average velocity matrices have been updated online in order to reduce computational burden. In addition, the calibration maps are recalculated every 10 seconds, which is completely affordable for the control equipment employed.

The evolution of the $\lambda$ parameter shown in the upper plot of Figure 11 allows the adaptive calibration strategy to keep the $\mathrm{NO}_{\mathrm{x}}$ emissions around the $\mathrm{NO}_{\mathrm{x}}$ constraint after some initial transient. It should be pointed out that the $\mathrm{NO}_{\mathrm{x}}$ emissions in $\mathrm{g} / \mathrm{km}$ are calculated from the ratio between the $\mathrm{NO}_{\mathrm{x}}$ emitted and the distance covered from the beginning of the test. In this sense, during the first seconds of the cycle, the operating conditions have a strong impact 
on the $\mathrm{NO}_{\mathrm{x}}$ emissions in $\mathrm{g} / \mathrm{km}$ and the signal shows important variations. Note that when the vehicle is stopped and the engine is in idle, the instantaneous $\mathrm{NO}_{\mathrm{x}}$ emission in $\mathrm{g} / \mathrm{km}$ are theoretically infinity. As the cycle evolves and the buffer considered to calculate emissions increases, the effect of the operating conditions is progressively smoothed.

Regarding the fuel consumption, the adaptive strategy allows a reduction of $3.5 \%$. It points out the importance of calibrating the engine taking into account the specific operating conditions of the vehicle rather than considering standard cycles such as the NEDC.

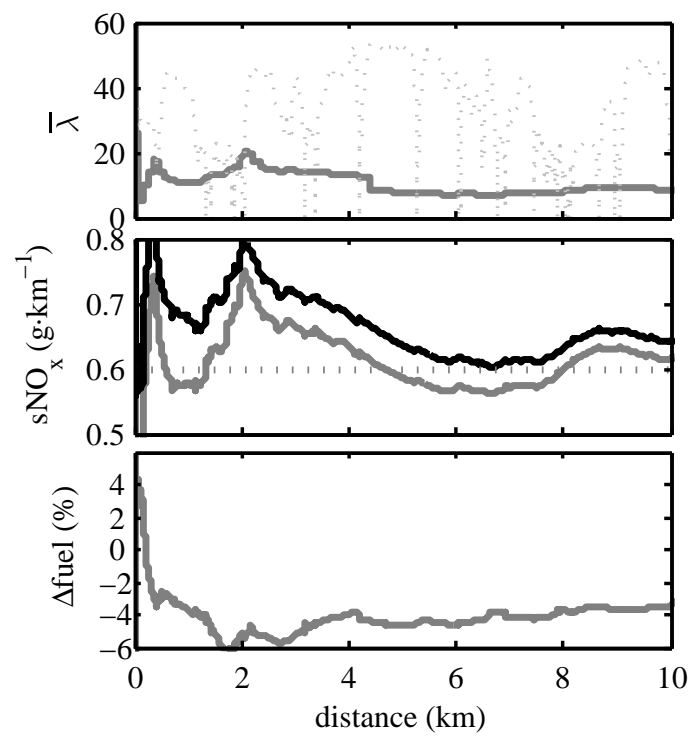

Fig. 11. Experimental results showing the evolution of the applied $\lambda$ parameter (upper plot), $\mathrm{NO}_{\mathrm{x}}$ emissions (medium plot) and difference in fuel consumption (lower plot) amongst tests with the proposed strategy with a $\mathrm{NO}_{\mathrm{x}}$ target of $0.6 \mathrm{~g} / \mathrm{km}$ (dark grey line) and the standard calibration (reference, black line).

Figure 12 shows the results obtained with the adaptive calibration strategy and two different $\mathrm{NO}_{\mathrm{x}}$ limits, namely $0.5 \mathrm{~g} / \mathrm{km}$ and $0.4 \mathrm{~g} / \mathrm{km}$, during an arbitrary cycle. It can be observed that for this particular cycle, independently of the $\mathrm{NO}_{\mathrm{x}}$ target, the cycle has an important impact on the current $\mathrm{NO}_{\mathrm{x}}$ emissions. In fact, it is shown that the emissions during the first part of the cycle are noticeably higher that in the second part. This is due to the fact that at the beginning of the test frequent stops appear. This driving style is common in small streets or during rush hours. At the second part of the cycle, the averaged velocity is higher, and the driving pattern corresponds to that observed in wide avenues. In any case, as far as the complete cycle is representative of the driver's average behaviour, the method is able to keep $\mathrm{NO}_{\mathrm{x}}$ emissions at $0.5 \mathrm{~g} / \mathrm{km}$.

Figure 13 shows the instantaneous evolution of $\mathrm{NO}_{\mathrm{x}}, \mathrm{MAF}$ and MAP. The top plot shows a comparison between the $\mathrm{NO}_{\mathrm{x}}$ emissions estimated by the quadratic model and the measured $\mathrm{NO}_{\mathrm{x}}$. The results show that despite there are some differences, the model tends to under-predict the $\mathrm{NO}_{\mathrm{x}}$, the general agreement is good. On the other hand, the comparison between set points and actual values for MAF and MAP show that the engine is able to follow the 


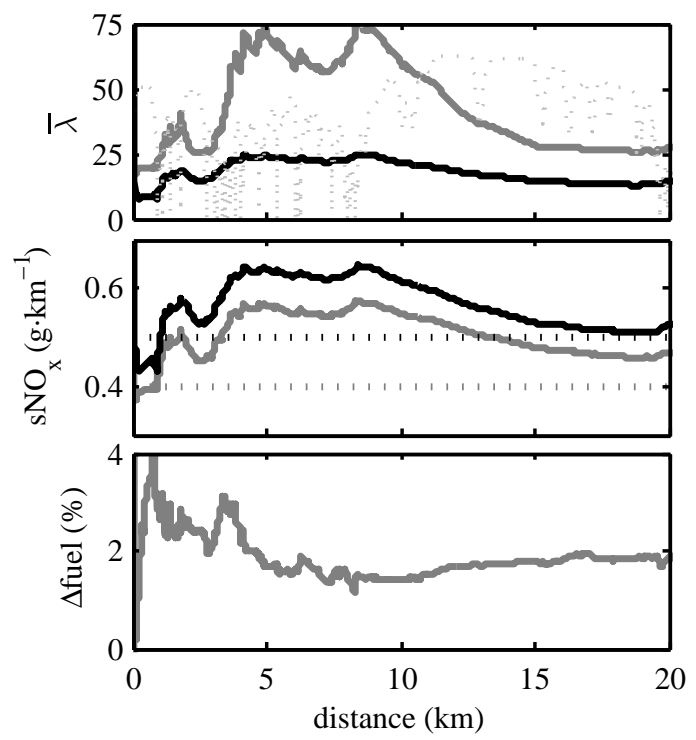

Fig. 12. Experimental results showing the evolution of the applied $\lambda$ parameter (upper plot), $\mathrm{NO}_{\mathrm{x}}$ emissions (medium plot) and difference in fuel consumption (lower plot) amongst tests with different $\mathrm{NO}_{\mathrm{x}}$ objectives: $0.5 \mathrm{~g} / \mathrm{km}$ (reference, black line) and $0.4 \mathrm{~g} / \mathrm{km}$ (dark grey line).

values demanded by the calibration.

In order to obtain better results different probability matrices should be used for areas \#1 and \#2, so the single probability matrix shown in Figure 4 could be replaced by a set of matrices mapped with the vehicle location (GPS) or discharged from common infrastructure (I2V) which manages the traffic information.

If a tightener $\mathrm{NO}_{\mathrm{x}}$ constraint is set, namely $0.4 \mathrm{~g} / \mathrm{km}$, the calibration is continuously adapted to reduce the $\mathrm{NO}_{\mathrm{x}}$ emissions. According to Figure 12, a reduction in $\mathrm{NO}_{\mathrm{x}}$ of about $0.1 \mathrm{~g} / \mathrm{km}$ involves an increase in fuel consumption of around $2 \%$ which correlates quite well with the modelling results.

However, in this particular cycle, the $\mathrm{NO}_{\mathrm{x}}$ target of $0.4 \mathrm{~g} / \mathrm{km}$ is not achieved. Analysing the evolution of the $\lambda$ parameter it can be concluded that its value should increase even more in order to reach the desired $\mathrm{NO}_{\mathrm{x}}$ level. The constant trend in the $\lambda$ value during the last phase of the cycle indicates that, according to the model, the applied calibration should keep the $\mathrm{NO}_{\mathrm{x}}$ in the desired limit, but measurements indicate the opposite. It is evidenced that the discrepancies between the model and the engine results are more important when the $\mathrm{NO}_{\mathrm{x}}$ limit is reduced and the applied calibration approaches the boundaries of the model identification.

The negative impact of model uncertainties on the results can be addressed by:

- Improving the model by using other methods or even including dynamics. It should be noted that considering dynamics complicates the optimisation method noticeably.

- Including an integral action in the feedback control law in (10). In this case, an additional term would be added to take into account the accumulated error. Despite this approach does not involve an increase in the model complexity, incorporating an integral term would involve some additional calibration effort.

In any case, the proposed method shows an important potential to adapt the engine calibration to the driver style 


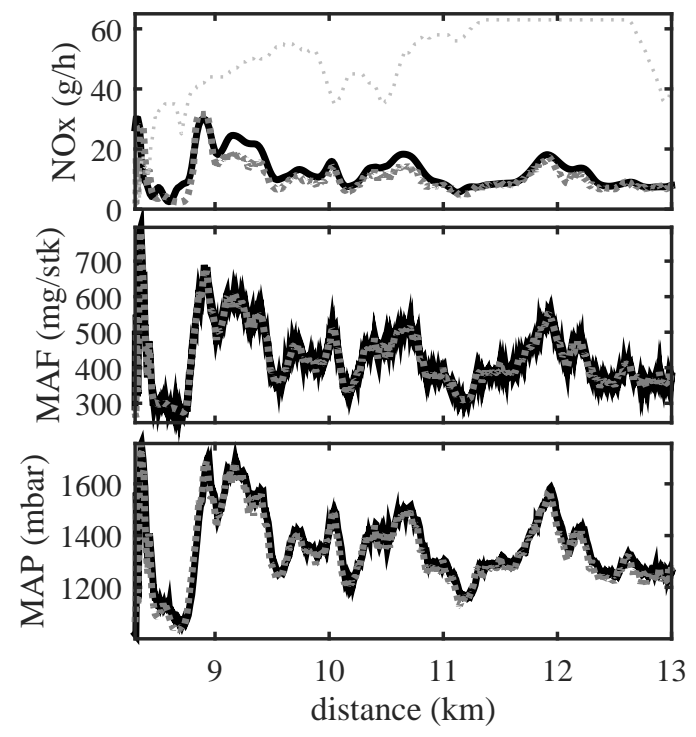

Fig. 13. Experimental results showing the evolution of the estimated (dotted line) and measured $\mathrm{NO}_{\mathrm{x}}$ emissions (black line) in the upper plot the comparison between the MAF set point (dotted line) and the actual MAF (black line) in the middle plot, and comparison between the MAP set point (dotted line) and the measured MAP (black line) at the bottom. Results obtained with a $\mathrm{NO}_{\mathrm{x}}$ objective of $0.5 \mathrm{~g} / \mathrm{km}$

and pollutant emissions requirements.

\section{CONCLusions}

A model based approach to the adaption of the engine calibration to the driver's behaviour and the required pollutant emissions has been presented. The proposed method is based on applying optimal control theory to obtain a set of calibrations able to minimise the fuel consumption while making the expected value of $\mathrm{NO}_{\mathrm{x}}$ emissions equal to different limits. The expected value of $\mathrm{NO}_{\mathrm{x}}$ emissions is calculated with a quasi-steady model and information about past engine speed and torque demands. The calibrations obtained may be mapped with the $\mathrm{NO}_{\mathrm{x}}$ emission limit, so the proper calibration is applied depending on the boundary conditions.

From author's point of view, important contributions of the proposed strategy are:

- The proposed strategy does not need additional experimental tests to that required by the traditional calibration approach.

- The method relies on information currently available in the ECU to adapt the engine calibration to the particular driving patterns of a given driver.

- Additional information about the emissions limits coming form an external structure can be easily employed.

- Despite the method does not involve an increase in the calibration effort, it involves an increase in ECU memory requirements since the calibration maps should be increased with an additional dimension $(\lambda)$.

The proposed strategy has been tested by simulation and finally it has been successfully implemented in a light-duty diesel engine. It has shown a good potential to keep $\mathrm{NO}_{\mathrm{x}}$ emissions around a given limit. 
Finally, the proposed strategy shows that non-negligible fuel consumption benefits can be obtained by relaxing the $\mathrm{NO}_{\mathrm{x}}$ emissions in those areas where pollution is not an issue. Conversely, the $\mathrm{NO}_{\mathrm{x}}$ emissions reduction implies an important penalty in fuel consumption that has been quantified in this paper.

\section{ACKNOWLEDGEMENT}

The authors would like to thank the valuable inputs and the thrilling discussions with Prof. Luigi del Re, Johannes Kepler Universität, Austria, and the original ideas on context aware control by Robert Shorten, Hamilton Institute, Ireland, which inspired the work.

\section{REFERENCES}

[1] F. Payri, J. Luján, C. Guardiola, and B. Pla, "A challenging future for the IC engine: new technologies and the control role," Oil \& Gas Science and Technology, 2014.

[2] L. Rubino, P. Bonnel, R. Hummel, A. Krasenbrink, U. Manfredi, and G. D. Santi, "On-road emissions and fuel economy of light duty vehicles using PEMS: Chase-testing experiment," SAE Paper 2008-01-1824, 2008.

[3] J. Galindo, H. Climent, C. Guardiola, A. Tiseira, and J. Portalier, "Assessment of a sequentially turbocharged diesel engine on real-life driving cycles," International Journal of Vehicle Design, vol. 49, no. 1-3, pp. 214-234, 2009.

[4] J.-M. Zaccardi and F. Le Berr, "Analysis and choice of representative drive cycles for light duty vehicles - case study for electric vehicles," Proceedings of the Institution of Mechanical Engineers, Part D: Journal of Automobile Engineering, vol. 227, no. 4, pp. 605-616, 2013.

[5] ECE, Proposal to develop a new global technical regulation on worldwide harmonized light vehicle test procedures, ece/trans/wp29/ac3/26 ed. United Nations. Economic commission for Europe. Inland Transport Committee. World Forum for Harmonization of Vehicle Regulations. Executive Committee (AC3) of the 1998 Global Agreement, 2009.

[6] R. Wang and S. M. Lukic, "Review of driving conditions prediction and driving style recognition based control algorithms for hybrid electric vehicles," pp. 1-7, September 2011.

[7] P. Mock, J. German, A. Bandivadekar, and I. Riemersma, "Discrepancies between type-approval and real-world fuel consumption and CO 2 values in 2001-2011 european passenger cars," The International Council on Clean Transportation, Tech. Rep., 2012.

[8] B. Daham, H. Li, G. Andrews, K. Ropkins, J. Tate, and M. Bell, "Comparison of real world emissions in urban driving for euro 1-4 vehicles using a PEMS," SAE Paper 2009-01-0941, 2009.

[9] B. Pla, H. Waschl, L. del Re, and C. Guardiola, "Fuel and immission potential of context aware engine control," in 2013 SAE World Congress, SAE Paper 2013-01-0306, 2013.

[10] M. Alsabaan, K. Naik, T. Khalifa, and A. Nayak, "Optimization of fuel cost and emissions with vehicular networks at traffic intersections," IEEE Conference on Intelligent Transportation Systems, Proceedings, ITSC, pp. 613-619, 2012.

[11] I. Iglesias, L. Isasi, M. Larburu, and A. e. a. Martin, "Networked clean vehicles, how the environment information will improve fuel efficiency and $\mathrm{CO}_{2}$ emissions," SAE Int. J. Fuels Lubr., vol. 2, no. 1, pp. 167-171, 2009.

[12] A. Ferrari, M. Chiodi, M. Bargende, and P. e. a. Roberti, "Virtual set-up of a racing engine for the optimization of lap performance through a comprehensive engine-vehicle-driver model," SAE paper 2011-24-0141, 2011.

[13] C. Guardiola, B. Pla, D. Blanco-Rodriguez, and A. Reig, "Modelling driving behaviour and its impact on the energy management problem in hybrid electric vehicles," International Journal of Computer Mathematics, 2013.

[14] R. Kamalanathsharma and H. Rakha, "Agent-based modeling of eco-cooperative adaptive cruise control systems in the vicinity of intersections," IEEE Conference on Intelligent Transportation Systems, Proceedings, ITSC, pp. 840-845, 2012.

[15] D. Lang, T. Stanger, and L. Del Re, “Opportunities on fuel economy utilizing V2V based drive systems,” SAE paper $2013-01-0985$, 2013.

[16] A. Malikopoulos and J. Aguilar, "Optimization of driving styles for fuel economy improvement," IEEE Conference on Intelligent Transportation Systems, Proceedings, ITSC, pp. 194-199, 2012.

[17] A. A. Malikopoulos, D. N. Assanis, and P. Y. Papalambros, "Real-time self-learning optimization of diesel engine calibration," Journal of Engineering Gas Turbines and Power, vol. 131, no. 022803, pp. 1-7, 2009. 
[18] R. Moos, "A brief overview on automotive exhaust gas sensors based on electroceramics," International Journal of Applied Ceramic Technology, vol. 2, no. 5, pp. 401-413, 2005.

[19] J. Riegel, H. Neumann, and H.-M. Wiedenmann, "Exhaust gas sensors for automotive emission control," Solid State Ionics, vol. 152-153, pp. 783-800, 2002.

[20] C. Guardiola, J. López, J. Martín, and D. García-Sarmiento, "Semiempirical in-cylinder pressure based model for NOX prediction oriented to control applications," Applied Thermal Engineering, vol. 31, no. 16, pp. 3275-3286, 2011.

[21] T. Johnson, "Review of $\mathrm{CO}_{2}$ emissions and technologies in the road transportation sector," SAE paper 2010-01-1276, 2010.

[22] C. Guardiola, B. Pla, D. Blanco-Rodriguez, and L. Eriksson, “A computationally efficient kalman filter based estimator for updating look-up tables applied to $\mathrm{NO}_{\mathrm{X}}$ estimation in diesel engines," Control Engineering Practice, vol. 21, no. 11, pp. 1455-1468, 2013.

[23] J. Arrègle, J. López, C. Guardiola, and C. Monin, “On board $\mathrm{NO}_{\mathrm{X}}$ prediction in diesel engines: A physical approach,” Lecture Notes in Control and Information Sciences, vol. 402, pp. 25-36, 2010.

[24] T. Nilsson, A. Froberg, and J. Aslund, "Optimal operation of a turbocharged diesel engine during transients," in 2012 SAE World Congress, SAE Paper 2012-01-0711, 2012.

[25] G. Rizzoni, L. Guzzella, and B. Baumann, "Unified modeling of hybrid electric vehicle drivetrains," IEEE/ASME Transactions on Mechatronics, vol. 4, no. 3, pp. 246-257, 1999.

[26] C. Guardiola, A. Gil, B. Pla, and P. Piqueras, "Representation limits of mean value engine models," Lecture Notes in Control and Information Sciences, vol. 418, pp. 185-206, 2012.

[27] T. Nesch, M. Wang, C. Voser, and L. Guzzella, "Optimal energy management and sizing for hybrid electric vehicles considering transient emissions," in IFAC Proceedings Volumes, 2012, pp. 278-285.

[28] C. Musardo, B. Staccia, S. Midlam-Mohler, Y. Guezennec, and G. Rizzoni, "Supervisory control for NO ${ }_{\mathrm{X}}$ reduction of an HEV with a mixed-mode HCCI/CIDI engine,” vol. 6, 2005, pp. 3877-3881.

[29] C. Guardiola, B. Pla, D. Blanco-Rodriguez, and P. Cabrera, "A learning algorithm concept for updating look-up tables for automotive applications," Mathematical and Computer Modelling, vol. 57, no. 7-8, pp. 1979-1989, 2013.

[30] Q. Zhang, A. Pennycott, and C. Brace, "A review of parallel and series turbocharging for the diesel engine," Proceedings of the Institution of Mechanical Engineers, Part D: Journal of Automobile Engineering, vol. 227, no. 12, pp. 1723-1733, 2013.

[31] E. Xavier, R. Westphal, and W. Rodrigues, "Reduction of experimental data points in the base calibration by estimation of engine maps using regularized basis function neural networks," SAE Technical Papers, 2012.

[32] M. Beham and D. Yu, "On-line control for optimal ignition timing using the pseudolinear radial basis function and the local linear model tree," Proceedings of the Institution of Mechanical Engineers, Part D: Journal of Automobile Engineering, vol. 219, no. 2, pp. 227-240, 2005.

[33] C. Manzie, M. Palaniswami, D. Ralph, H. Watson, and X. Yi, "Model predictive control of a fuel injection system with a radial basis function network observer," Journal of Dynamic Systems, Measurement and Control, Transactions of the ASME, vol. 124, no. 4, pp. 648-658, 2002.

[34] M. Hirsch and L. del Re, "Adapted D-optimal experimental design for transient emission models of diesel engines," in 2009 SAE World Congress, SAE Paper 2009-01-0621, 2009. 